\title{
Beyond Skills: An Integrative Approach to Doctoral Student Preparation for Diverse Careers
}

\author{
Susan D. Porter \& Jennifer M. Phelps \\ University of British Columbia
}

\begin{abstract}
An early consensus in the ongoing discourse about graduate student preparation for diverse careers was that graduates lacked competencies relevant to non-academic professional settings. Lists of missing "skills" were developed that universities and agencies sought to address, most commonly by the offering of generic (transferable) skills workshops or courses. In this paper, we critique this framing of the issue and discuss the limitations of the common approaches taken to address it. We propose a more integrated approach, where students' thesis research itself is oriented to their possible futures (a practice already occurring in many areas), and where assessment of the competencies so developed is integral to the awarding of the degree. We illustrate the concepts through the stories of two students, and discuss policy ramifications and the substantial challenges to its realization presented by a highly competitive research environment and established ways of assessing success in faculty and students.
\end{abstract}

\section{Résumé}

Dans le débat toujours actuel à l'égard de la préparation des étudiants des études supérieures à leur entrée sur le marché du travail, le consensus qui s'en dégageait au départ était que les étudiants diplômés ne disposaient pas des compétences pertinentes aux milieux professionnels non universitaires. Devant ces conclusions, les universités et agences de placement ont cherché à combler ce « manque de compétences », surtout au moyen de cours et d'ateliers 
de compétences générales (transférables). Nous offrons ici une critique de cette façon de répondre au problème et nous discutons des limites des façons courantes de l'aborder. Nous proposons une approche plus intégrée pour perfectionner ces compétences, approche par laquelle la thèse de l'étudiant s'oriente précisément vers l'avenir vocationnel de celui-ci (une pratique déjà courante dans plusieurs domaines). L'évaluation des compétences ainsi développées devient indispensable à la remise du diplôme. Nous illustrons ces concepts par le truchement de deux études de cas. De manière plus générale, nous discutons des ramifications politiques potentielles de cette approche, ainsi que des défis importants liés à sa réalisation dans un milieu de recherche hautement concurrentiel, et mettons en pratique des moyens d'en évaluer la réussite.

Publicly funded institutions of higher learning have a responsibility to prepare scholars, to make a positive difference in society. The premise of this issue of CJHE is that our educational approaches have not kept pace with the rapidly evolving realities of our graduate students' increasingly diverse post-graduation career outcomes. By remaining entrenched in traditional modes of education oriented solely towards preparation for the academy, we are failing to meet both our students' and society's expectations of how those who reach the pinnacle of formal education can contribute meaningfully to advancing the public good through a variety of career pathways.

When these issues were brought to the fore, globally, over a decade ago, a call went out to provide training that would enable graduates to build a portfolio of tools beyond those required for a career in academia. Extracurricular, "generic" professional development programs were established widely (and in the UK, recommended as mandatory), which provided support for the development of competencies in areas such as management, communication, and entrepreneurship. Our own institution, The University of British Columbia, has had a program of this nature in place for more than ten years that we have been deeply involved in shaping. From our own experiences as graduate administrators (dean and assistant dean) and those reported by our colleagues working in similar programs across Canada and beyond, we know that these offerings are typically appreciated by students and may very well have helped in post-graduation transitions to the workforce, although research on this relationship is scarce. We argue, however, that the effectiveness of such programs for graduates' ultimate work performance is unproven and that purely skills-focused training, tacked on as an adjunct to students' primary development as scholars oriented to academe, is insufficient. Further, the trend towards orienting the discourse on doctoral education so exclusively to useful skills development (e.g., Leitch, 2006; Conference Board of Canada, 2013) runs the risk of constraining our views on the multidimensionality of learning that is possible and desirable at the doctoral level.

As others have also argued, doctoral education is at its best and most comprehensive when approached as a process of formation as opposed to mere skills training. Walker et al. (2008), writing on behalf of the Carnegie Initiative on the Doctorate, describes formation thusly:

Formation, in contrast [to training], points not only to the development of intel- 
lectual expertise but to the growth of "the personality, character, habits of heart and mind" and "the role that the given discipline is capable of and meant to play in academe and society at large" (Elkana, 2006, pp. 66, 80). What is formed, in short, is the scholar's professional identity in all its dimensions. (p. 8)

Rather than reductively framing the purpose of doctoral education as a process of skill acquisition or separating this unquestionably valuable component from the academic endeavour itself, we are instead attracted to the potential of structuring doctoral education as an integrative and formative experience involving the comprehensive enrichment of professionals within and beyond the academy, with development not only in scholarship, knowledge, and discrete skills but also in their connection to a larger context and sense of purpose. Many students we interact with regularly indicate that it is this comprehensive, more fully relevant educational experience that they are seeking in doctoral study.

In this paper, we explore this broader conceptualization of doctoral education and critique the prevalent approach to skills acquisition in graduate education. We propose a more integrated approach to the development of career-relevant competencies, using examples of purposeful (although incomplete) integration of formative experiences into the core academic activities of disciplinary graduate education. We close with a discussion of the ramifications of such changes for academic policy and student assessment and of the substantial challenges to their realization. Similar proposals have recently been made in the context of the humanities $\mathrm{PhD}$ (Institute for the Public Life of Arts and Humanities, McGill University, 2013; Modern Language Association of America, 2014). This paper extends this concept to all disciplines and places the discussion in a pedagogical framework.

\section{The "Skills" Discourse Pivot}

It is now a broadly accepted notion that graduate education must change to meet the shifting needs of $21^{\text {st }}$ century graduates and society. This idea gained initial traction in the 1990 and early 2000 s with many major projects and reports produced in the US (Golde \& Dore, 2001; National Academy of Sciences, 1995; Nyquist \& Woodford, 2000; Walker et al., 2008; Woodrow Wilson Foundation, 2005), the UK (HEFCE, 1996; Leitch, 2006; Roberts, 2002; UK Grad Programme, 2001), Australia (Kemp, 1999), and Europe (Sörlin, 1996; EUA, 2005). Themes common to these projects included the growing diversity of graduate career outcomes, employer-identified gaps in the abilities of $\mathrm{PhD}$ graduates to contribute meaningfully in non-academic environments, and student-identified gaps in their preparation for and employability in careers outside of academia. These reports critiqued the narrowness of doctoral research, its lack of connection to a larger social context, and academics' weak understanding of professional life outside the university. Further criticisms focused on the dearth of transferable professional attributes of $\mathrm{PhD}$ graduates: many new PhDs lacked experience in teamwork; they did not have an entrepreneurial attitude or relevant know-how; and they did not appreciate the need to be able to communicate ideas to audiences beyond their disciplinary peers. To identify what was missing in the traditional doctorate, lists of deficient "skills" (typically categorized as "transferable" or "generic") were created and generally included communication, interpersonal skills, and management.

The impulse to specify desired graduate attributes is understandable and can be help- 
ful in pedagogical design. The increasingly prioritized value of "skills" as a graduate outcome, however, risks replacing rich conceptions of higher learning with a reductive goal of being able to do. We note that characteristics of creativity, subtlety of thought, breadth of understanding, motivation, empathy, willingness to take risks, integrity, tenacity, and insight are all fruits of the best education, valuable in their own right, and important for those pushing the boundaries of human understanding. Some may maintain that a broad definition of "skills" encompasses these attributes, but this assertion arguably muddies the discourse, not least because of the different pedagogical approaches relevant to the development of these attributes (Gilbert et al., 2004). More deeply, the lists encourage both educators and students to fragment their approaches to learning, thereby losing sight of students' growing professional identity and the interconnectedness of their knowledge, values, intellect, and performance.

Additionally, the common transferrable skills discourse often ignores the ways that even concrete abilities are extraordinarily dependent on context. A skilled person is so identified if their performance as a particular actor in a particular social arena is interpreted as skilled within a normative framework (Holmes, 2006; Wolf, 1991). For example, the ability to communicate complex information to non-experts may apply to the relaying of research results in an op-ed piece, to informing staff about a change in direction, or to creating a briefing paper for stakeholder review. Each of these requires a diverse set of competencies, attributes, and types of knowledge, as well as an appreciation of one's identity in the particular context. True transferability of higher level skills is a matter of significant debate (Bridges, 1993; Bastalich, 2010; Gilbert et al, 2004; McWilliam \& Singh, 2002), and in the above examples, there is no easily conceived single transferable skill (e.g., "communication") giving rise to accomplished performance in each of these contexts. Related problems with the typical lists of generic skills are that they tend to oversimplify or sometimes misrepresent employers' interpretations of deficiencies in employee performance (Bastalich, 2010; Cumming, 2010; Hinchliffe, 2013; Holmes, 2001) and that they may not have the same meaning among those charged with delivering curricula (Barrie, 2006).

\section{Graduate Professional Development Programming and Curricula}

Most major universities and some external organizations (e.g. Vitae in the UK, Mitacs in Canada) now offer generic graduate student professional development programs. Typically, these are offered as stand-alone "how-to" workshops for multidisciplinary audiences, for example: "Dealing with Difficult Personalities in Your Organization" (McGill University SKILLSETS program), "Managing Effective Collaborative Research Teams" (UBC Graduate Pathways to Success Program), "Effective Networking" (Mitacs Step program). Our experience is that these are highly valued by students, who are often anxious about their preparation for post-graduate life, in that they gain some confidence and practical tips from this exposure. For a number of valid reasons, however, there is little research on the efficacy of these instructional interventions beyond the assessment of participants' perceptions.

We believe there are benefits to this type of programming, at the very least, in raising awareness of the scope of development possible and helpful in the student's formation. It cannot be the only or even the primary solution, however, to the problem outlined in this journal's issue. Apart from the difficulty associated with the meaningful assessment 
of competency, there are several fundamental limitations to this approach. The typically decontextualized nature of the instruction risks glossing over real disciplinary or contextual differences in skillful practice (Barnacle \& Dall'Alba, 2011; Wolf, 1991). Also, insofar as this approach "untethers the relation between knowledge and practice" (Barnacle \& Dall'Alba, 2011, p. 463), it does not help the learner to identify the appropriate contexts for application. Without contextualized application and practice, the extent of meaningful learning is questionable.

\section{Integrated Approaches to Forming Professional Identity}

In contrast to the typical, fragmented approaches to skills development, integrative learning fosters learners' abilities to make connections across time and between domains of knowledge, skills, and contexts, and to build a capacity greater than the sum of the learning parts. Integrative learning has long been endorsed in the educational community for its ability to build "habits of mind that prepare students to make informed judgments in the conduct of personal, professional, and civic life" (Huber \& Hutchings, 2004, p. 1). This connective ability is at the core of the best scholarship,

whether focused on discovery and creativity, integrating and interpreting knowledge from different disciplines, applying knowledge through real-world engagements, or teaching students and communicating with the public (Boyer, 1990). Done well, these facets of scholarship all require taking account of different dimensions of a problem, seeing it from different perspectives, and making conceptual links among those dimensions and perspectives (Suedfeld et al., 1992). (Huber \& Hutchings, 2004, pp. 1-2)

Graduate research degree programs are characterized by such integrative learning. In most disciplines, however, these abilities are cultivated and then assessed only as they relate to conducting research in an academic setting. Given that most PhD graduates will not obtain tenure-track positions and that approximately half will not work in academia at all across all disciplines, in at least North America and Western Europe (Auriol et al., 2013; Desjardins, 2012; Desjardins \& King, 2011; National Science Foundation, 2010), we propose that development and assessment of PhD scholarship should more frequently engage points of integration not simply within the academic context but also between academia and other environments.

During the PhD experience, there are numerous potential approaches for integrating learning relevant to scholarship into non-academic or non-research, "alternative academic" settings. These include coursework relevant to these contexts, internships in alternative settings, applied or externally engaged volunteer experiences, consulting or related professional activities relevant to the discipline, and embedding research undertaken in non-academic settings in the thesis work itself. Many of these, along with co-curricular professional development programming, form the core of a number of significant Canadian and international initiatives focused largely on enhancing research students' competencies in non-academic settings. Of these approaches, integration of academic and alternative domains occurs at the deepest level when the thesis work itself consists in part or in whole of work in different settings.

What might the characteristics of an integrated $\mathrm{PhD}$ be? If the formation of profes- 
sional identity is key to the purpose of the degree, then, drawing on Walker et al. (2008) and Elkana (2006), an understanding and integration of the attitudes, sensibilities, values, knowledges, and skills relevant to the setting-of the "habits of heart and mind" and the role of the discipline in that setting-will be critical. An integrated $\mathrm{PhD}$ requires active and deliberate mentorship in the professional context, embedding within the professional culture, and assessment of the attributes necessary for effective and creative intellectual achievement in that setting. The competencies developed are not a side-product of the PhD program but an integral, assessable part of it.

Aspects of this model are already common in the more applied disciplines where research relationships with non-academic bodies are natural and expected, and many faculty members across various disciplines are already well connected to and working within more applied settings. The one aspect that is not common, however, even with applied academic work, is the deliberate and integrated assessment of knowledge and competencies required for successful practice in the professional field(s). In the same way that PhD students are now assessed on aspects of their academic professional identity such as their ability to craft research grant proposals and write academic papers, perhaps the assessment of competencies relevant to other professional settings can also be included. For those in industry settings, for example, students' research is assessed through the incorporation of the results in the thesis, but the relevant modes of communication and translation could also be assessed by requiring in the thesis or comprehensive exam a customer-development process or business model. For work relevant to public policy, assessment might address a student's ability to distill and translate their research in the form of a policy paper. A history student might integrate their research into a museum setting by working with a museum to produce a curatorial proposal as part of the thesis.

This concept of integration was one of the three major themes of the Carnegie Initiative on the Doctorate and was exemplified by the incorporation of both basic and pedagogical research in a thesis. The authors also urged a re-thinking of thesis structures: "the time is ripe to break the dissertation mold and find forms better matched to the functions of scholarly life in diverse professional settings" (Walker et al., 2008, p. 152). Although murmurings of profound changes needed in the thesis are becoming more common, we are not aware that they have yet been implemented. A recent White Paper proposing a more applied focus for the humanities PhD (Institute for the Public Life of Arts and Humanities, McGill University, 2013) suggests jettisoning the thesis altogether in these applied pathways and replacing it with a "coherent ensemble of projects" (p.19). Given that theses in many disciplines are already in fact an ensemble of interrelated projects that may also be presented as discrete academic papers, the distinction may be semantic. However, it raises fundamental questions about the depth of research appropriate for the $\mathrm{PhD}$ degree. We anticipate a fascinating discourse on these matters in the years to come.

\section{Examples from the Frontier of Integration}

The PhD journeys of Michelle Kooy, a UBC alumna, and Jennifer Won, a current UBC student, illustrate many of the concepts of integration presented here. Michelle became known to us when we canvassed our UBC colleagues for examples of students who were deeply integrating professional work into their doctoral research. Jennifer works in the academic discipline of this article's lead author, through which they became acquainted. We 
chose to share their particular stories in this article as apt illustrations of the benefits and challenges of pursuing "integrated PhDs" in two very different academic disciplines and professional settings, although we do not assert that they are necessarily representative of any broader trends or student experiences. Their narratives were collected via personal communication with the authors, and their names and reports are shared with permission.

Michelle completed her PhD in geography in 2008. Her thesis focused on problems in urban water access in Jakarta, where she spent most of her time as a student. She worked closely with a number of local NGOs there, as well as banks, development contracting agencies, and other professionals, in order to document access to safe water supply, explain variations in levels of access across urban population groups, and gain access to appropriate projects and communities. She was intent on a non-traditional academic career from the start, with a desire to be more engaged in issues outside the academy than she felt could be accommodated in a traditional academic career. During her PhD, Michelle worked as a technical advisor for one of the NGOs, where she reported receiving "superb" mentorship in the professional setting. Immediately after graduation, she was hired by the NGO as Director of Urban Programs. She has since worked as an international development policy researcher at a UK think tank and is currently a senior lecturer at UNESCO-IHE. When asked what she learned from her experience working with the NGOs and other bodies during her $\mathrm{PhD}$, Michelle provided a lengthy list: project and financial management, stakeholder analysis, participatory urban planning, written and oral communication skills for cross-cultural and non-academic audiences, proposal writing, leadership, and monitoring and evaluation. She produced numerous communication products, including policy briefs, proposals, newsletters, project reports, and a UNDP background paper. Although she did not feel she had received formal mentorship in research or its translation in Jakarta, she stated she had been mentored "in the sense of what it means to make a total life commitment (with sacrifices)." Michelle viewed these gains as separate from those developed in the academic context and as contributing immeasurably to her preparation for work (and life) in that context.

Our second example, Jennifer Won, is in the fifth year of her $\mathrm{PhD}$ in pathology and laboratory medicine. Her initial research project examined the association of a series of biomarkers with cancer types using the technique of immunohistochemistry, the results of which have potential utility in cancer diagnosis. By the time she had finished this initial project, Jennifer had decided that she was not interested in an academic career. Her supervisor encouraged her to explore other career options and to consider how the remainder of her thesis research might be oriented towards her interests. Jennifer discovered she was interested in the work of a group of clinicians in Vancouver hospitals who had recently initiated a grant-funded quality assurance (QA) program in immunohistochemistry for hospital laboratories across Canada. With the backing of the QA group, Jennifer and her supervisor brought a proposal to her supervisory committee to re-orient her thesis towards this application. Although the committee had concerns that not everyone in their discipline would view this as appropriate thesis material (and hence that examiners would have to be chosen carefully), they fully approved. She proceeded to work with the QA group to design and implement a project to assess whether the biomarkers she had identified earlier could be used with accuracy and diagnostic utility by Canadian laboratories. Her interest in QA was cemented during this time, and the group discovered that 
she was a tremendous asset to them. They developed a business plan to allow Jennifer to be hired as their first scientific director. She is now directing this project, including the associated publicity and business structure. In addition to academic papers generated from this work, Jennifer wrote test reports for the participating laboratories, business grant applications, and a press release. She is now employed in this capacity as she completes her thesis, and she "can honestly say that [she] approach[es] the duties of each day with genuine excitement."

Reflecting on what she learned during her time with the QA group, Jennifer said that it was "eye-opening" and that she developed a strong desire to "help the cause" of quality in hospital laboratories. She also learned how to write business grants and began to appreciate how business principles are incorporated in the work they do. She has honed her accounting skills, she continues to learn, as she says, "how to do the dance" and speak the language of the business environment, and she increasingly appreciates how important it is to communicate with the labs in a way that gets their attention.

Elements common to Michelle and Jennifer's experiences include not only the development of their scholarship applied to different contexts, but the development of their professional identities, as described previously (Walker et al., 2008). Their experiences fostered new "habits of heart and mind," a new appreciation for the role of their discipline and scholarship in these contexts, and new skills relevant to the profession. Although students who complete internships may also develop these attributes and skills, because many of these opportunities are unconnected with thesis work or do not deeply embed the students in the professional environment, it is likely that such development would be less profound and would not integrate the full range of their intellectual capacities with the professional ethos.

Michelle and Jennifer's experiences, however, were not fully integrated into their academic program. Both were enthusiastic about their context-specific learning, but both also felt that much of it was an add-on to their work as PhD students. Michelle believed it lengthened her completion time. Both would have appreciated being able to incorporate the professional products of their work (the policy briefs, public reports, business plans, etc.) into their theses, and they felt that they would have benefited from feedback on these elements. According to Michelle, including them in her thesis would have "mentally helped [her] to give them the time and attention they deserved, without having guilt about 'taking time away' from the 'real' thesis/PhD process." She also felt it would have been helpful for employment purposes to have had these professional products more formally evaluated. Given that many faculty members would not have the expertise to evaluate the students' professional abilities and products rigorously, mentors from the professional community could act in this capacity. Having these individuals participate as actual supervisory committee members would more fully integrate academic and professional learning.

\section{Implications of and Barriers to the Integrated PhD}

The strong orientation of Jennifer and Michelle towards making a real-world impact not only after but also during their doctoral education is consistent with that of many graduate students. A study by Phelps (2013) found that a wide majority of international doctoral student participants intended for their doctoral work to increase their capacity to make positive social contributions. Here, the term "social" was used broadly to encom- 
pass many contexts, including those that directly impact civil society in addition to those in related dimensions of global benefit, such as environmental sustainability and animal welfare. Participants linked their ability to make these contributions to their attainment of the doctoral degree, and several stated that advancing social causes was an explicit motivation in their decision to engage in doctoral education. However, in the findings of many of the major doctoral projects listed previously and in our own experience, PhD students frequently find the traditional academic paradigm to be a limitation to their linked ambitions of rigorous scholarship and social contribution.

Although the pace of change varies by discipline, there is an increasing recognition that universities have much to offer society by engaging with the public sphere and with real-world problems, and that they benefit immensely from this engagement. Indeed, they are more frequently being viewed as irrelevant, and perhaps even irresponsible, if they avoid such real-world involvement. Programs have sprung up in recent years to facilitate this engagement, and granting councils increasingly require evidence of impact on broader society. Thus, there seems to be a growing capacity and willingness to embrace the applied orientation of the PhD discussed here, and the graduates of such programs may well be more competitive in the academic market than traditional scholars with no experience outside the walls of academia.

The concept of the more applied $\mathrm{PhD}$ is not without its detractors and raises legitimate concerns about the perceived purpose of the university and its research. The public good of the university should not be defined by its contribution to economic growth or even to the resolution of social problems:

[I]n so far as we allow the value of research to be determined by its immediate usefulness to the corporation or the state we devalue the development of the imagination-whether scientific, humanistic, or practical. The defense of higher education needs to be made on the basis of the full development of the human imagination and of public higher education on the full development of the capacity and experience of the citizen. (Meranze, 2009, noted by Mitchell, 2011, p. 160)

The university serves the world in part by providing an intellectual space for inquisitiveness, imagination, and "independent reflection upon prevailing culture, rather than reflecting back to that culture its own priorities and values" (Bastalich, 2010, p. 852). Might the options for the PhD envisioned here threaten to delegitimize or reduce the capacity for curiosity-driven research and independent inquiry so central to the mission of the university? Do we run the risk of diminishing scholarship or of focusing it so intently on application that we would lose the ability to explore the complexity of the fundamental questions of nature and humanity? In answer, we suggest that there is space within research relationships with external partners and use-inspired research for independence, imagination, curiosity, and deep scholarship (see Stokes, 1997). We also note that the applied focus should by no means be the only available (or even the most prevalent) pathway and that PhD students should continue to have opportunities to address fundamental questions with no immediate or direct relevance to society. It is our belief, however, that even those students who do not develop overt applications of their work during their study can be assisted in surfacing the tacit value of their deep disciplinary expertise and related abilities and in orienting these attributes towards diverse career pathways.

There are also practical barriers to implementing this new PhD. Although an increas- 
ing number of faculty members are well placed and inclined to pursue these forms of research and are able to assess students' work products or performance in relation to professional settings, many are not prepared to offer meaningful support to students interested in these pathways. A more effective approach may be to include individuals from the partner setting as formal mentors in the student's academic program and assessment processes, thus reducing the need for all faculty members to be experts in the non-academic work. Lastly, universities may begin to place greater value on external experience in hiring faculty, and with $\mathrm{PhD}$ graduates' likely increasing expertise in such domains, this trend may eventually become normative.

Another real barrier is academia's publish-or-perish culture, in which the faculty reward system is dominated by the production of refereed publications. A PhD program of research oriented towards a professional context might not generate the number or type of co-authored academic publications expected from a traditional $\mathrm{PhD}$ pathway in many disciplines. Some supervisors may be disinclined to mentor students on these alternative pathways if it means less work is accomplished on their research grants. These are perhaps the most intractable problems, and the new $\mathrm{PhD}$ will not likely catch on unless there is some resolution to these issues. As discussed above, there are forces already at work that are increasingly shifting the culture of academia, and we anticipate that the impact of research will continue to be assessed more broadly. $\mathrm{PhD}$ students on these partnered pathways may very well move forward their supervisors' research agendas by facilitating academic and non-academic collaborative research ventures.

Those universities willing to invest further in enabling these pathways will need to revise their policies on thesis and, possibly, comprehensive exam structures, and they may need to revisit policies on supervisory and examination committee membership as well. They will need to educate thesis examiners on the purpose and structure of these theses, and they might consider dedicated funding for students to allow for greater independence from their supervisors' academic grant mandates. Tracking graduate outcomes and showcasing the diversity of what success looks like will be critical, as will the continuing, more nuanced measurement of research impact for promotion and tenure. The university will also need to encourage and support faculty members to mentor in this fashion and to celebrate the exemplars who have done so.

The integrative concepts explored here are equally applicable for those interested in academic teaching as they are for those oriented towards non-academic careers. Instead of exploring the public policy implications of research, students could develop competencies in teaching through mentored projects, incorporating syllabi or pedagogical research in the thesis or comprehensive assessment. The same approaches could also be used productively for master's students who are performing research and for postdoctoral fellows.

Although the distinction between the $\mathrm{PhD}$ and professional or practice-oriented doctorates may be blurring, we are not advocating for the consideration of the $\mathrm{PhD}$ as vocational training. We believe the $\mathrm{PhD}$ should continue to represent the height of university scholarship, and its relevance to awardees should not be limited to particular professional contexts. Graduates are not expected to remain in single employment settings their entire lives and, as exemplified by Michelle's career, may well move in and out of academia. Integrating knowledge and perspectives from diverse real-world settings with the scholarship of the university has benefits well beyond the preparation of graduates for single career pathways. 


\section{Conclusions}

We have argued that in order to best serve both the interests of doctoral students entering a wide range of professional careers and the society that depends upon highly educated individuals to serve the public good effectively, the time has come for PhD studies and for the professional development of doctoral students to become more deeply integrated within a holistic doctoral education experience. Such integration occurs at the deepest level when the full range of attributes, knowledges, and competencies necessary for success in students' eventual careers is developed and assessed in the context of their growth as scholars. This broader integration, much of it already happening in many areas of academe, requires a substantial re-thinking of the traditional modes of graduate education and the endorsement of those responsible for it. It requires enlightened mentorship that recognizes and nurtures the ambitions of emerging scholars; flexibility in doctoral program requirements; a broader definition of the impact of research; interdisciplinary and globally connected initiatives that expand perspectives; and a learning culture in the academy that embraces different ways of expressing new knowledge.

\section{References}

Auriol, L., Misu, M. \& Freeman, R. A. (2013). Careers of doctorate holders: Analysis of labour market and mobility indicators. OECD Science, Technology and Industry Working Papers, No. 2013/04, OECD Publishing.

Barnacle, R. \& Dall'Alba, G. (2011). Research degrees as professional education? Studies in Higher Education, 36(4), 459-470.

Barrie, S. C. (2006). Understanding what we mean by the generic attributes of graduates. Higher Education, 51(2), 215-241.

Bastalich, W. (2010). Knowledge economy and research innovation. Studies in Higher Education, 35(7), 845-857.

Bogle, D., Dron, M., Eggermont, J., van Henten, J. W. (2010). Doctoral degrees beyond 2010: Training talented researchers for society. League of European Research Universities. Retrieved from http://www.leru.org/files/publications/LERU_Doctoral_ degrees_beyond_2010.pdf

Bridges, D. (1993). Transferable skills: a philosophical perspective. Studies in Higher Education, 18(1), 43-51.

Boyer, E. L. (1990). Scholarship reconsidered: Priorities of the professoriate. San Francisco, CA: Jossey-Bass.

Conference Board of Canada. (2013). Skills-where are we today? Post-secondary education and the state of skills production in Canada. Retrieved August 2014 from http:// www.conferenceboard.ca/Libraries/EDUC_PUBLIC/spse_nov2013_summitpaper_ skills.sflb

Cumming, J. (2010). Contextualised performance: Reframing the skills debate in research education. Studies in Higher Education, 35(4), 405-419.

Desjardins, L. (2012). Profile and labour market outcomes of doctoral graduates from Ontario universities. Statistics Canada. Catalogue no. 81-595-M-No. 098. 
Desjardins, L. \& King, D. (2011). Expectations and labour market outcomes of doctoral graduates from Canadian universities. Statistics Canada. Catalogue no. 81-595-M-No. 089.

Elkana, Y. (2006). Unmasking uncertainties and embracing contradictions: Graduate education in the sciences. In C. Golde \& G. Walker (Eds.), Envisioning the future of doctoral education: Preparing stewards of the discipline-Carnegie essays on the doctorate (pp. 65-96). San Francisco, CA: Jossey-Bass.

European University Association (EUA). (2005). Bologna seminar on "Doctoral programmes for the European knowledge society." Conclusions and recommendations. Retrieved March 2014 from http://www.eua.be/eua/jsp/en/upload/Salzburg_ Conclusions.1108990538850.pdf

Gilbert, R. (2004). A framework for evaluating the doctoral curriculum. Assessment \& Evaluation in Higher Education, 29(3), 299-309.

Gilbert, R., Balatti, J., Turner, P. \& Whitehouse, H. (2004). The generic skills debate in research higher degrees. Higher Education Research \& Development, 23(3), 375-388.

Golde, C. M., \& Dore, T. M. (2001). At cross purposes: What the experiences of today's doctoral students reveal about doctoral education. A survey initiated by the Pew Charitable Trusts. Retrieved March 2014 from http://www.phd-survey.org/report\%20 final.pdf

Higher Education Funding Council for England (HEFCE). (1996). Review of postgraduate education. London, Higher Education Funding Council for England, Committee of Vice-Chancellors and Principals and Standing Conference of Principal.

Hinchliffe, G. (2013). Employability: A capability approach. In A. Boni \& M. Walker (Eds.), Human Development and capabilities: Re-imagining the university of the twenty-first century (pp. 82-96). Abingdon, UK: Routledge.

Holmes, L. (2001). Reconsidering graduate employability: The "graduate identity" approach. Quality in Higher Education, 7(2), 111-119.

Holmes, L. (2006, May). Reconsidering graduate employability: Beyond possessiveinstrumentalism. In 7th International Conference on HRD Research and Practice Across Europe, University of Tilburg.

Huber, M. T. \& Hutchings, P. (2004). Integrative learning: Mapping the terrain. Washington, DC: Association of American Colleges and Universities.

Institute for the Public Life of Arts and Ideas. (2013, December). White paper on the future of the PhD in the humanities. Montreal, QC: McGill University.

Kemp, D.A. (1999). New knowledge, new opportunities: A discussion paper on higher education research training. Canberra, AU: Commonwealth of Australia. Retrieved March 2014 from http://www.voced.edu.au/content/ngv23061

Leitch, S. (2006). Prosperity for all in the global economy-world class skills. Final report. London, UK: HM Treasury. Retrieved March 2014 from http://webarchive. nationalarchives.gov.uk/+/http://www.ukces.org.uk/upload/pdf/2006-12\%20 LeitchReview1_2.pdf 
McWilliam, E. \& Singh, P. (2002). Towards a research training curriculum: What, why, how, who? Australian Educational Researcher, 29(3), 4-18.

Meranze, M. (2009). Higher education as a public good. Remaking the university [web log]. Retrieved from http://utotherescue.blogspot.ca/2009/11/higher-educationas-public-good.html

Mitchell, D. (2011). The entrepreneurial university. In B. Zelizer (Ed.), Making the university matter (pp. 154-161). Abingdon, UK: Routledge.

Modern Language Association of America. (2014). Report of the MLA Task Force on Doctoral Study in Modern Language and Literature. Retrieved from http://www.mla. org/pdf/taskforcedocstudy2014.pdf

National Academy of Sciences. (1995). Reshaping the graduate education of scientists and engineers. Washington, DC: National Academy Press.

National Science Foundation. (2010). Survey of doctorate recipients. Retrieved August 2014 from http://ncsesdata.nsf.gov/doctoratework/2010/

Nyquist, J. D. \& Woodford, B. J. (2000). Re-envisioning the PhD: What concerns do we have? Seattle, WA: University of Washington Center for Instructional Development and Research. Retrieved from http://depts.washington.edu/envision/resources/ ConcernsBrief.pdf

Phelps, J. (2013). Otherwise, elsewhere: International doctoral students in globalized, transnational spaces. Unpublished doctoral dissertation, The University of British Columbia, Vancouver. Available at: https://circle.ubc.ca/handle/2429/44158

Stokes, D. E. (1997). Pasteur's quadrant: Basic science and technological innovation. Washington, DC: Brookings Institution Press.

Suedfeld, P., Tetlock, P. \& Streufert, S. (1992). Conceptual/integrative complexity. In C. Smith (Ed.), Motivation and personality: Handbook of thematic content analysis (pp. 393-400). Cambridge, UK: Cambridge University Press.

Roberts, G. G. (2002). SET for success: The supply of people with science, technology, engineering and mathematics skills-The report of Sir Gareth Roberts' Review. London: HM Treasury. Retrieved from http://dera.ioe.ac.uk/4511/

Sörlin, S. (2006). A public good: PhD education in Denmark. Report from an international evaluation panel. Ministry of Science, Technology and Innovation. Retrieved from http://ufm.dk/en/publications/2006/files-2006/a-public-good-phd-education-indenmark.pdf

UK GRAD Programme. (2001). Joint statement of skills training requirements for research students. Retrieved from http://www.grad.ac.uk/downloads/documents/ general/Joint\%20Skills\%2oStatement.pdf

Walker, G. E., Golde, C. M., Jones, L., Bueschel, A. C., \& Hutchings, P. (2008). The formation of scholars: Rethinking doctoral education for the twenty-first century. San Francisco, CA: Jossey-Bass.

Wolf, A. (1991). Assessing core skills: Wisdom or wild goose chase? Cambridge Journal of Education, 21(2), 189-201. 
Woodrow Wilson National Fellowship Foundation. (2005). The responsive PhD: Innovations in US doctoral education. Retrieved from http://woodrow.org/news/ publications/responsive-phd/

\section{Contact Information}

Susan Porter,

Faculty of Graduate and Postdoctoral Studies

University of British Columbia

susan.porter@ubc.ca

Susan D. Porter, PhD, is dean and vice-provost, Graduate and Postdoctoral Studies, and a clinical professor in the Department of Pathology and Laboratory Medicine at the University of British Columbia. She has been engaged in the administration of graduate education since 2000 and has a long-standing interest and involvement in graduate student and postdoctoral professional development.

Jennifer M. Phelps, PhD, is assistant dean, Student Administration and Strategic Initiatives at the University of British Columbia and had previous professional roles within California State University and University of California system campuses. Her recent research focuses on the choices and experiences of international doctoral students as transnational actors within a globalized higher education context. 